\title{
Liebe Leserin, lieber Leser,
}

als wir Mitte 2012 die Schwerpunkte dieses Jahres planten war bereits absehbar, dass das Thema „Roma in Deutschland“ wegen der bevorstehenden uneingeschränkten Arbeitsnehmerfreizügigkeit für rumänische und bulgarische Staatsbürger äußerst aktuell sein würde. Inzwischen ist die Situation in einigen Großstädten noch brisanter als seinerzeit gedacht. Im „Durchblick“ beleuchten wir u.a. am Beispiel Duisburgs die Bedingungen, unter denen Roma gegenwärtig in Deutschland leben.

Bei der Arbeit an diesem Schwerpunkt ist mir wieder einmal aufgefallen, wie häufig und schnell „den Medien“ eine vermeintlich einseitige oder gar absichtlich „falsche“ Berichterstattung angelastet wird (Stichwort: „Manipulation“). Aus meiner Sicht ist das eine problematische, weil zu passive Haltung: wer an der öffentlichen Darstellung etwas ändern möchte, muss sich beteiligen („einmischen“), und zwar mediengerecht. Hier beobachte ich bei Sozial Arbeitenden vielfach ideologische Vorbehalte bzw. handwerkliche Defizite. Es reicht jedenfalls nicht, Gutes zu tun, man muss auch darüber sprechen. Und zwar möglichst so, dass man auch verstanden wird. Dazu ist es z.B. notwendig, zeitgerecht geeignetes Material zur Verfügung zu stellen. Überdies gibt es ja inzwischen nicht mehr nur die konventionellen „Altmedien“, sondern es ist auch recht einfach möglich, Botschaften über andere Kanäle zu verbreiten: Aktion statt Reaktion. Statt einer resignierenden Medienschelte wäre meiner Meinung nach eine Überprüfung bzw. Anpassung der eigenen Kommunikationsstrategien produktiver.

In „Praxis aktuell“ geht es in dieser Ausgabe um Möglichkeiten

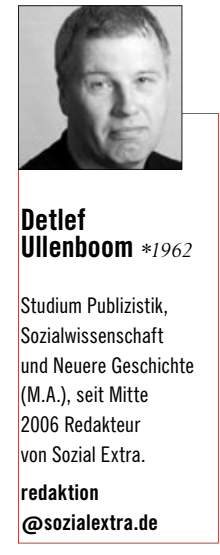
und Anwendungsbereiche ethnografischer Methoden. In diesem Bereich haben Medien eine herausgehobene Bedeutung. Vielleicht ergibt sich durch die intensivere Beschäftigung damit ja auch eine neue Wahrnehmung und Interpretation von „Medienmacht“? Für einen kompetenten, selbstbewussten Einsatz von Medien im beruflichen Alltag wäre dies jedenfalls förderlich.

Besinnliche Weihnachtstage und alles Gute für das kommende Jahr wünscht

Detlef Ullenboom 